Journal of Case Reports 2020;10(4):220-222

\title{
Common Variable Immune Deficiency
}

\author{
Nehal Aggarwal, Ankit Gupta, LH Ghotekar, Shubhalaxmi Margkar, Ramesh Aggarwal, Priya Bansal \\ Department of Medicine, Lady Hardinge Medical College and associated Smt. Sucheta Kriplani Hospital, New Delhi, India.
}

\begin{abstract}
Corresponding Author:
Dr. Priya Bansal

Email: priyasingal@gmail.com

This is an Open Access article distributed under the terms of the Creative Commons Attribution License (creativecommons.org/ licenses/by/3.0).
\end{abstract}

$\begin{array}{lll}\text { Received } & : & \text { May 14, 2020 } \\ \text { Accepted } & : & \text { August 19, 2020 } \\ \text { Published } & : & \text { October 20, 2020 }\end{array}$

\begin{abstract}
Background: Common variable immunodeficiency (CVID) is an immune disorder characterized by recurrent infections, low antibody levels and varied presentations. Case Report: We present a case of common variable immune deficiency (CVID) which is a rare disorder and is characterized by recurrent bacterial infections in adults. Our patient had been suffering from recurrent skin and soft tissue infections and pneumonia since five years. He was diagnosed with CVID and started intravenous immunoglobulins. He has been stable with improved quality of life since discharge. Conclusion: A strong index of suspicion in patients presenting with recurrent skin-soft tissue and sino-pulmonary infections leading to timely diagnosis and treatment of CVID can be rewarding.
\end{abstract}

Keywords: Bacterial Infections, Common Variable Immunodeficiency, Immunologic Deficiency Syndromes, Infections, Pneumonia.

\section{Introduction}

Common variable immunodeficiency syndrome (CVID) is a heterogeneous disorder characterised by diminished levels of $\operatorname{IgG}, \operatorname{IgA}$ and/or IgM, and recurrent bacterial infections. The disorder apparently results from immune deregulations resulting in failed B-cell differentiation with impaired secretion of immunoglobulins. CVID commonly presents as recurrent bacterial infections caused by encapsulated bacteria, the most common ones being skin infections, sinusitis, otitis media, bronchitis and pneumonia.

\section{Case Report}

A 28-year-old male presented with high-grade fever and dry cough for ten days, accompanied with right sided pleuritic chest pain and breathlessness on exertion for last five days. He had discharging pustular lesions over his chin twenty days ago and diarrhea for three days around that time. He gave a history of recurrent oral ulcers over the last five years, occurring every 2-3 weeks. He had past history of being diagnosed with severe nutritional anemia, both iron and megaloblastic anemia, five years ago with hemoglobin of $3 \mathrm{~g} / \mathrm{dL}$, and was managed with three units of packed cells, iron and vitamin $B_{12}$ supplementation which led to recovery to normal values. He developed pneumonia two years ago for which he was admitted to a hospital and received intravenous antibiotics. He also has a history of recurrent abscesses in both his axillae which required incision and drainage along with antibiotics. The patient gives no family history of similar complaints. There was no history of allergies or recurrent sinusitis.

On examination, he was thin built, temperature was $99.8^{\circ} \mathrm{F}$, pulse rate $116 / \mathrm{min}$, respiratory rate $32 / \mathrm{min}$ with a blood pressure of $110 / 58 \mathrm{mmHg}$. His oxygen saturation was $95 \%$ on room air. Physical examination revealed pallor, bilateral pitting pedal edema and impetigo lesions on his chin. He had no clubbing or nasal polyps. On chest auscultation, there were bronchial breath sounds and crepitations in the right mammary and 
axillary areas. Rest of the physical examination was within normal limits.

Laboratory investigations revealed a raised total leucocyte count of $25400 / \mathrm{mm}^{3}$, with $93 \%$ polymorphs. His hematological and biochemical parameters were haemoglobin $9.3 \mathrm{~g} / \mathrm{dL}$ with a MCV $93 \mathrm{fL}$, ESR $37 \mathrm{~mm} / \mathrm{hr}$, serum protein and albumin were 3.9 and $2.3 \mathrm{~g} / \mathrm{dL}$ respectively, and total cholesterol and LDL was 84 and $37 \mathrm{mg} / \mathrm{dL}$ respectively. Liver and kidney function tests were normal. A chest roentgenogram showed right upper and middle zone homogenous patchy consolidation with right sided tracheal deviation. Arterial blood gas (ABG) showed a $\mathrm{pH}$ of 7.5, $\mathrm{PCO}_{2}$ of $32 \mathrm{mmHg}$, $\mathrm{PO}_{2}$ of $68 \mathrm{mmHg}$ and $\mathrm{HCO}_{3}$ of $25 \mathrm{mEq} / \mathrm{L}$. In view of right sided pneumonia, patient was started on intravenous ceftriaxone and azithromycin and topical mupirocin for impetigo.

A contrast enhanced CT of the chest revealed areas of consolidation with air bronchogram in the right upper and middle lobe with ill-defined centrilobular nodules, bronchial wall thickening with mild bilateral pleural effusion suggesting infective etiology and also mediastinal lymphadenopathy with the largest having a short axis diameter of $16 \mathrm{~mm}$. CT abdomen was grossly normal. Gram stain, AFB and cultures for induced sputum, blood cultures and Mantoux test revealed no contributory findings. The patient showed clinical improvement over subsequent days. Given the patient's recurrent lower respiratory infections, recurrent purulent infections (abscesses, impetigo) and malnutrition, we suspected an underlying immunodeficiency disorder. However, HIV and viral markers were negative. Iron studies, vitamin $\mathrm{B}_{12}$ and folic acid levels were normal. Peripheral smear showed normocytic normochromic anemia. Stool for occult blood was negative and so were antinuclear, alpha 1 antitrypsin and anti-tissue transglutaminase antibodies. His immunological profile showed decreased levels of all the immunoglobulins. Ig levels were below detection limits (normal 700-1445 mg/dL), IgA 1.56 mg/
$\mathrm{dL}$ (normal 70-400 mg/dL) and IgM $4.72 \mathrm{mg}$ / $\mathrm{dL}$ (normal 35-250 mg/dL). This confirmed the diagnosis of CVID and patient was given $400 \mathrm{mg} /$ $\mathrm{kg}$ of intravenous immunoglobulin (IVIG) for 5 days and started on monthly regimen of IVIG. The diagnosis of CVID was further confirmed by an inadequate antibody response to pneumococcal vaccine and tetanus toxoid. Since initiation of this regimen eighteen months ago, the patient has required no further hospital admissions or antibiotic treatment, and has reported a significant improvement in quality of life.

\section{Discussion}

Common variable immunodeficiency (CVID), also known as acquired hypogammaglobulinemia, is a type of primary humoral immunodeficiency. It's a rare disease with an incidence varying from 1 in 10,000 to 1 in 50,000 and equal in both sexes. CVID is a heterogeneous disease characterised by diminished levels of immunoglobulin A, IgG and/or $\operatorname{IgM}$ and diminished antibody response to vaccination [1]. After selective IgA deficiency, CVID is the second most common immunodeficiency disorder. Majority of the patients present in their $2^{\text {nd }}$ or $3^{\text {rd }}$ decade. However, in view of varied clinical presentations the diagnosis is delayed by up to 6 to 8 years [2]. The diagnosis of CVID is made mostly by excluding secondary causes of immunodeficiency and other primary immunodeficiency disorders after extensive workup. European Society for the Immunodeficiency's (ESID) Criteria for the diagnosis of CVID is onset of immunodeficiency at greater than 2 years of age with a marked decrease of IgG (at least $2 \mathrm{SD}$ below the mean for age) and a marked decrease in at least one of the isotypes IgM or IgA in the absence of defined causes of hypogammaglobulinemia.

The pathogenesis of the disorder results from impaired B-cell differentiation, formation of plasma cells and resultant immunoglobulins [3]. Patients with CVID may also present abnormalities 
in helper $\mathrm{T}$ cell function and in dendritic and monocytic compartments [4]. CVID commonly presents as recurrent bacterial infections caused by encapsulated bacteria [3], the most common ones being sinusitis, otitis media, bronchitis and pneumonia. Extra-pulmonary manifestations of CVID include recurrent diarrhea (most common being Giardia, Campylobacter), inflammatory bowel disease, protein-loss enteropathy, sprue-like syndrome, autoimmune disorders like idiopathic thrombocytopenic purpura and autoimmune haemolytic anemia, and malignancy like lymphoma and gastric cancer. Presence of bronchiectasis and liver disease at diagnosis carries a poor prognosis in CVID patients. Untreated patients can develop sepsis or meningitis, which can be fatal [3].

The need for early diagnosis of this disorder lies in the fact that it responds well to 400 to $600 \mathrm{mg} / \mathrm{kg}$ body weight per month intravenous immunoglobulin (IVIG) thus preventing complications. Those with recurrent infections despite IVIG therapy may benefit from suppressive antibiotic therapy especially azithromycin given three times a week. IgG levels should be checked periodically to attain a target trough level. Autoimmune and granulomatous diseases do not respond to IVIG. Corticosteroids, cyclosporine A, infliximab, etanercept and rituximab have shown significant efficacy in some reports $[1,5,6]$.

\section{Conclusion}

The case presented here emphasizes the need for a high index of clinical suspicion for CVID in patients presenting with recurrent skin-soft tissue and sinopulmonary infections. Although IVIG provides improvement in these patients, early diagnosis is the key to preventing significant morbidity and mortality and improving prognosis.

Contributors: NA: manuscript writing, literature review, and diagnosis; AG, SM, PB: manuscript editing, references and patient management. RA, LHG: critical inputs into the manuscript and patient management. $\mathrm{PB}$ will act as a study guarantor. All authors approved the final version of this manuscript and are responsible for all aspects of the study.

Ethical Approval: Written informed consent has been taken from the patient's family. The presentation has been cleared by the department's ethics committee.

Funding: None; Competing interests: None stated.

\section{References}

1. Tarzi MD, Grigoriadou S, Carr SB, Kuitert LM, Longhurst HJ. An approach to the management of pulmonary disease in primary antibody deficiency. Clin Exp Immunol. 2008;155:147-155.

2. Maarschalk-Ellerbroek LJ, Hoepelman AI, van Montfrans JM, Ellerbroek PM. The spectrum of disease manifestations in patients with common variable immunodeficiency disorders and partial antibody deficiency in a university hospital. J Clin Immunol. 2012;32:907-921.

3. Cunningham-Rundles $\mathrm{C}$, Bodian C. Common variable immunodeficiency. Clinical and immunological features of 248 patients. Clin Immunol. 1999;92:34-48.

4. Cunningham-Rundles C, Radigan L, Knight AK, Zhang L, Bauer L, Nakazawa A. TLR9 activation is defective in common variable immune deficiency. J Immunol. 2006;176:1978-1987.

5. Bates CA, Ellison MC, Lynch DA, Cool CD, Brown KK, Routes JM. Granulomatous-lymphocytic lung disease shortens survival in common variable immunodeficiency. J Allergy Clin Immunol. 2004;114:415-421.

6. Ardeniz Ö, Başoğlu ÖK, Günşar F, Ünsel $M$, Bayraktaroğlu S, Mete $\mathrm{N}$, et al. Clinical and immunological analysis of 23 adult patients with common variable immunodeficiency. J Investig Allergol Clin Immunol. 2010;20:222-236. 